As part of the 50th birthday celebration, we are arranging to reprint 12 papers, the editor's choice, which have appeared in previous issues of the fournal. They have been chosen partly to illustrate the range and scope of the fournal over the years and partly because they are or were important in their day. More significantly, they have been chosen because they exemplify some of the best in scientific writing and can all be read with great pleasure and all who wish to communicate their observations, their ideas, or their enthusiasms would do well to study them and learn from them.

We will publish one paper each month through the year and they will appear in the order in which they were originally published.

Editor's Choice

\title{
Chronic mercury poisoning
}

by Monamy Buckell, Donald Hunter, Reginald Milton, and Kenneth M A Perry

(British fournal of Industrial Medicine 1946;3:55-63)

It would hardly be possible to imagine a selection of papers from the fournal that did not contain at least one by Donald Hunter, the first editor. Hunter, who was never himself an occupational physician in the sense that he was never employed in industry, nevertheless had the most profound effect on occupational medicine. His pre-eminent place was due in large measure to his Diseases of Occupations, which appeared first in 1955 and went through six editions before his death. There can have been few, if any, textbooks of medicine that were such a pleasure to read and that were so full of good advice. Even now the section on the social history of occupational health is worth a read. If the later editions of the book started to show their age, this is perhaps the occupational hazard which besets the author of a big popular work. The new, multiauthored continuation of the book bears little resemblance to the original in style or readability and in my view would best be called something else. It is such a pity that there is no longer anyone with either the breadth of knowledge or the writing ability to produce another work in the same class.

The second way in which Hunter had such an influence was through his students, several of whom became-or remain-prominent in occupa- tional medicine. Unfortunately I never knew Hunter but my first boss, A R Thompson, who was chief medical officer at Vauxhall Motors had been a student at the London Hospital and had a vivid recollection of Hunter's lectures which were remembered by all present long after the event.

The paper reprinted here is a classic study of chronic mercury poisoning which, surprisingly, given its long history, had never been fully investigated in industry. The paper contains a splendid description of the toxic organic psychosis produced by mercury in which "the man affected is easily upset and embarrassed, loses all joy in life and lives in constant fear of losing his job. He has a sense of timidity and may lose self control before visitors ... if one stops to watch such a man in a factory, he will sometimes throw down his tools and turn in anger on the intruder, saying he cannot work if watched. . . Drowsiness, depression loss of memory and insomnia may occur, but hallucinations, delusions and mania are rare."

The description of the method for measuring urinary mercury concentrations in the paper is a good example of the elaborate techniques that were necessary in the days before atomic absorption spectrophotometry and the rest which now make capturing the stray molecule in any body fluid so (comparatively) easy. 